Journal of Education and Vocational Research

Vol. 3, No. 4, pp. 127-131, Apr 2012 (ISSN 2221-2590)

\title{
Poole's Stochastic IS-LM Model and Optimal Monetary Policy Rule: A Framework for Graduate Teaching
}

\author{
Amaresh Das \\ College of Business, Southern University New Orlean, USA \\ adas2@cox.net
}

\begin{abstract}
Our comment revisits Poole's popular exposition of the IS-LM model and proceeds to extend the discussion to best derive the optimal monetary policy rule. The key assumption is that the economy is closed with no transactions in goods and capital. This will help us better understand the basic working of the macro economy.
\end{abstract}

Keywords: IS-LM model, expected loss function, gradient algorithm

\section{Introduction}

The IS-LM model that describes the dynamics of economics in the short-run. It has millions of critiques and rightly so... However, even though from the theoretical point of view, it has some loopholes, it continues to be an excellent way of analyzing and understanding the behavior of economics. Therefore, it is a regular topic in first year graduate macroeconomics. Robert Solow when he was at The Council of Economic Advisors was once asked: 'what of all of your knowledge did you use the most?' His answer was something like this: 'well, you just need the Dornbusch and Fischer but you have to use it right.' In practical policy, making the IS-LM dominates at least 50 percent of macro discussions. ${ }^{1}$ The most important assumption required for this model to work is that prices (in particular wages) are fixed. However, movement in economic policies cannot explain short-run fluctuations. It is unlikely that the government wants to create a recession by decreasing government expenditure or by restricting money supply. Furthermore, short-run fluctuations have the property that they are not fully predictable. This means that short-run fluctuations, booms and recessions have some random components that makes them not completely predictable or pre determined in the short run. Poole's model is a stochastic version of the IS-LM model which comprises an equation representing the IS curve and equation representing an LM curve, each with an additive error. Poole then shows that if there are 'exogenous' shifts on the expenditure side of the economy (the IS curve is volatile), use of money as an instrument yields a smaller variance for income than use of the interest rate instrument. Conversely, if there are 'exogenous' shifts in the demand for money (the LM curve is volatile), the use of an interest rate instrument results in a smaller income variance than if money is chosen as instrument. If both IS and LM curves are volatile, the choice between money and interest rate will depend on the relative size of the shocks to the IS curve and LM curve ( both variance and covariance of stochastic disturbance) as well as the parameters of both equations as all these elements are needed to calculate the variance of income. What is the one point that needs to be emphasized about the Poole's approach? Poole assumes that the policy maker sees only the results of stochastic shocks in the form of movements of interest rates or money and his specific information regarding a source of optimality that may arise in the system.

The source of in optimality, according to Poole may be due to the conditional variance $v[y(t) \mid x(t)]$ of the state or the target variable $y(t)$ may not be independent of the instrument or the control variable $x(t)$. There may be other sources of optimality, for instance, some of the parameters like $\sigma$, either in the objective function or the system equation may not be completely known, so that some methods of learning may have to

1 The IS-LM model is often called optimizing IS-LM model, because it can be built up from micro foundations. It is alternatively called expectation IS-LM model because the traditional model's behavioral equations are modified to include expectation terms suggested by micro foundation and also, because, it is analyzed using rational expectations, see for recent references King et al (1998), Kimball 91995), Tinsley (1993) 
be built into any decision rules that are to be practically applied. Instead of going into a general theory, we can present an illustrative example, which seems relevant for selecting optimal monetary and fiscal policies in a macroeconomic framework. The Volcker disinflation of 1979-1982, and countless other examples, makes it clear that the short run and long run effects of monetary policy are much different. In the short run, monetary expansion lowers interest rates by increasing the level of liquidity in financial markets. In the end, faster money growth raises inflation and thus raises nominal interest rates, with no effect on the real rate. Experience suggests that if the central bank is too closely connected to the government, short run considerations will dominate with possible adverse consequences in the longer term (unnecessarily high inflation). As a result, many countries give the central bank some autonomy, much as we do for the judiciary, e.g., the US Supreme Court Justices are appointed for life, and members of the Board of Governors of the Federal Reserve System are appointed for 14-year terms (we will discuss the Federal Reserve System in more detail later on). This gives elected officials control, in the longer term, over monetary policy, but insulates monetary policy from day-to-day politics. Over the last decade or so, there has been increasing pressure in Congress to make the Fed more "accountable." Articles in the Wall Street Journal and elsewhere note that monetary policy is made by people who have not been elected, suggesting that perhaps they should be ${ }^{2}$.

\section{Poole's Model}

Consider the problem of optimal choice of the monetary instrument $\mathrm{m}_{t}$ or the fiscal instrument $r_{t}$, where the equilibrium state equation is either

$\begin{aligned} y_{t} & =a_{1} y_{t-1}-a_{2} y_{t-2}-a_{3} m_{t}+e_{t} \\ 0 r & y_{t}=b_{1} y_{t-1}-b_{2} y_{t-2}-b_{3} r_{t}+\bar{e}_{t}\end{aligned}$

Here $\mathrm{y}_{\mathrm{t}}$ is real national income, $\mathrm{x}_{1 \mathrm{t}}=\mathrm{m}_{\mathrm{t}}, \mathrm{x}_{2 \mathrm{t}}=\mathrm{r}_{\mathrm{t}}$ are the two instruments, $\mathrm{e}_{\mathrm{t}}$ and $\overline{\mathrm{e}}_{\mathrm{t}}$ are the additive stationary disturbances. The objective function for system optimization is the expected loss function

$$
\mathrm{L}_{0}=\mathrm{EL}(\mathrm{y}, \mathrm{x})=\mathrm{E}\left(\mathrm{y}_{\mathrm{t}}-\mathrm{y}^{0} \mid \mathrm{x}_{\mathrm{it}}\right)^{2}
$$

Conditional on the choice of the instrument $x_{i t}, i=1,2$ where $y^{0}$ is the desired value of the target pre assigned exogenously. This simple framework has been discussed by Poole (1970), Turnovsky (1975) and others, for example, Das (2010) with the simplifying assumption that the bivariate distribution $P$ $\left(y_{t}, x_{i t}\right)$ is normally independently distributed, i. e. , the conditional variance $v\left(y \mid x_{i t}\right)$, since

$\mathrm{L}^{0}=\mathrm{v}\left(\mathrm{y}_{\mathrm{t}}-\mathrm{y}^{0}\right)^{2}$

2 Should the Fed be more accountable to Congress? The evidence seems to be that in those countries with more independent central banks, inflation has been lower and unemployment has not been much different. In this sense, independence may be a good idea. That is generally the recommendation to high inflation countries: deny the fiscal authority access to the printing presses by making the central bank independent. The low inflation rates of Germany are surely the result of an extremely independent Bundesbank, which does not seem to have affected them adversely in other respects. German output growth, for example, has been as good as any European country in the postwar period. It is strange, then, that Congress would then argue that Fed independence is bad for the US. It is hard, too, to resist a further cheap shot at Congress: would you rather put monetary policy in the hands of the Greenspan and Co., or the people who brought you the S\&L fiasco? 
For any bivariate distribution $\mathrm{P}\left(\mathrm{y}_{\mathrm{t}}, \mathrm{x}_{\mathrm{it}}\right)$ whether normal or not, the assumption of conditional normality implies that the first term on the right-hand side of 1 (d) is a constant independent of the instrument variable $x_{i t}, i=1,2$ and hence the optimal control rule satisfies

$$
E\left(y_{t}\right)=y^{0}
$$

In addition, if variance $v\left(y_{t}-y^{0} \mid x_{1 t}\right)>\left(y_{t}-y^{0} \mid x_{2 t}\right)$, then the second instrument $x_{2 t}=r_{t}$ is chosen to be optimal. Otherwise, the first is chosen. The indifference zone arises when the two conditional variances are equal, which, of course, is most unlikely.

\section{An Extension}

Suppose we have some parameters like $\phi$ are unknown. For example, the loss function may be

$$
\mathrm{L}(\alpha, \mathrm{y}, \mathrm{x})=1 / 2\left[\alpha^{\prime} \mathrm{z}-\mathrm{w}\left(\phi^{*} \mathrm{z}\right)\right]^{2} \quad 2(\mathrm{a})
$$

When the output $\mathrm{y}$ and control $\mathrm{x}$ are subsumed in the vector $\mathbf{z}$ and the vector $\mathbf{x}$ is assumed to be a stationary multivariate process with a density function $\mathrm{P}(\alpha)$. The average risk functional is then

$$
\mathrm{R}(\mathrm{Z})=\mathrm{E}_{\alpha} \mathrm{L}(\alpha, \mathrm{z}) ; \mathrm{z} \in \mathrm{Z}
$$

Where the set may be viewed as a set of constraints on control or state and $\mathrm{E}$ is the expectation over the random components $\alpha$. Minimization of R (Z) in 2 (b) will involve the unknown parameter $\phi^{*}$ is the scalar function $\mathrm{w}\left(\phi^{*}, \mathrm{z}\right)$ and hence the optimal decision rule concerning a policy cannot be completely specified unless some estimate of $\phi^{*}$ is built up from sample observations ${ }^{3}$. Bayesian methods provide updating of a priori estimates through additional sample observations, for example, in the normal case a posterior estimate can be explicitly computed. When the scalar functions, $\mathrm{w}\left(\phi^{*}, \mathrm{z}\right)$ is a polynomial in $\mathrm{z}$ of a given degree and the parameters $\phi^{*}$ enter as coefficients in this polynomial, we have to solve a non-linear program. If there were no constraints on $\mathrm{z}$, the optimal value of $\phi^{*}$ would be obtained from the necessary condition. ${ }^{4}$

$$
\mathrm{v} R(\mathrm{z})=\mathrm{v} R\left(\mathrm{z}, \phi^{*}\right)=0 .
$$

\footnotetext{
${ }^{3}$ See Boyd and Vandenberghe (2004), it is an excellent book for getting into convex optimization.

${ }^{4}$ Under some regularity conditions, the expected value of $\mathrm{V}$ with respect to the observation $X$, given $\theta$, written $E(V / \theta)$, is zero. To see this rewrite the likelihood function $L(\theta ; X)=f(X ; \theta)$ as probability density function.

$E(V / \theta)=\int_{-\infty}^{+\infty} \frac{\frac{\delta f(x ; \theta)}{\delta \theta}}{f(x ; \theta)} f(x ; \theta) d x=\int_{-\infty}^{+\infty} \frac{\delta f(x ; \theta)}{\delta \theta} d x$

If certain differentiability conditions are met, the integral may be rewritten as

$\frac{\delta}{\delta \theta} \int_{-\infty}^{+\infty} f(x ; \theta) d x=\frac{\delta}{\delta \theta} 1=0$

It is worth restating the above result in words: the expected value is zero. Thus, if one were to repeatedly sample from some distribution, and repeatedly calculate the score, then the mean value of the scores would tend to zero as the number of repeat samples approached infinity.
} 
The gradient condition 2(c) may be specified explicitly, if the probability distribution $P(\alpha)$ of the random component is not known. We have to introduce, therefore, an algorithm of learning to provide an estimate of $\mathrm{z}=\hat{\mathrm{z}}(\mathrm{s})$ and the associated values of $\phi^{*}=\widehat{\phi}(\mathrm{s})$ that converges in time to their optimal values $\mathrm{z}^{0}$, $\phi^{0}$, say, by successive observations on $\alpha=\widehat{\alpha}(\mathrm{s}), \hat{\mathrm{y}}(\mathrm{s}) . \mathrm{vR}[\hat{\mathrm{z}}(\mathrm{s})]$. A suitable discrete algorithm in this case could be defined in terms of a modified gradient algorithm, for example,

$$
\bar{\phi}=\bar{\phi}(\mathrm{s}-1)-\mathrm{h}(\mathrm{s}) \mathrm{vL}[\mathrm{z}(\mathrm{s}), \bar{\phi}(\mathrm{s}-1), \alpha(\mathrm{s})]
$$

With the objective function min R (z) replaced by

$$
\operatorname{Min} R\{\hat{z}(S)\}=R\{\hat{z}[\widehat{\phi}(S)]\}]=1 / S \sum_{s=1}^{S} \operatorname{L}\{\hat{z}(s), \bar{\phi}(s), \widehat{\alpha}(s)\} \quad 2(d)
$$

Where the search is restricted within the set $\widehat{z}(s) \in$ Zand the term, h (s) above for the step length must be appropriately chosen for convergence purposes ${ }^{5}$. Alternative search methods thus provide alternative learning rules, (for example, see Tsykpin (1973), Bouquet et al (2004)) which need to be compared before one decides on the final optimal rule.

\section{Implications and discussion}

May we explore by way of a discussion that the idea that changes in the households' and firms' optimism and confidence about the economy (animal spirits) can lead to self-fulfilling recessions or economic booms even if the fundamental determinants of income and interest rates have not changed. Suppose that suddenly households and firms become more pessimistic about the future of the economy. This change is the market mood or confidence may occur even if there has been no change in the current fundamentals. For example, households may start to cut consumption even if the level of their disposable income is unchanged and the level of interest rate is unchanged. This reduction in consumption (in spite of the constancy of the determinants of consumption, disposable income and interest rates) may occur if there is an event that makes households more pessimistic about their future income. For example, when Iraq invaded Kuwait in the summer of 1990, the U.S. economy started to go into a recession. Why? Part of the story is that households were nervous about the 'random' effects of the invasion on the economy and started to cut their consumption spending in spite of the fact that their current incomes and interest rates were unchanged. This exogenous reduction in consumption led to a fall in aggregate demand; in turn, this fall in aggregate demand led to a fall in production that resulted in the recession of 1991-1992. In other terms, an exogenous change in consumer confidence about the future of the economy led to a self-fulfilling recession. Similar changes in optimism, investor's mood (otherwise called by Keynes 'animal spirits' and consumer confidence may lead to changes in the firms' investment demand even if fundamental determinants of investment (such as real interest rates) have not changed. Firms may suddenly become concerned about the uncertainty of the economy and this change in firms' animal spirits may or may not be related to actual changes in the current state of the economy. If this change in firms' sentiment occurs, they may start to cut their investment (their purchases of plant and equipment). This fall in investment demand, in turn, leads to a fall in aggregate demand and a selffulfilling fall in output. i.e. a recession may end up occurring just because consumers and firms start to believe that a recession might be occurring in the future. One can easily formalize the idea of self-fulfilling changes in output due to animal spirits in the context of output stochastic IS/LM model?

\footnotetext{
${ }^{5}$ Statistical learning theory is an ambiguous term: It may refer to computational learning theory, which is a sub-field of theoretical computer science that studies how algorithm can learn from data. Here we refer to updating of probability distribution as new information is gained, using Bayes' theorem as in recursive Bayesian estimation. A considerable literature appeared regarding the problem of developing the posterior or approximate posterior distribution while incorporating structural form information, see Zellner (1971), Hastie et al (2008),
} 


\section{Conclusion}

We have seen that the conditional variance of the state variable may not be independent of the control variable. There may be other sources of non-optimality arising from some of the parameters being unknown in the objective function. The specification of the numerical parameter is of crucial importance. The problem is also, therefore, empirical. Here we have provided an example as to why and how to learn to choose an optimal policy rule in a macroeconomic framework. We abstracted from the effects of estimation error or random variation in the coefficients of the model and from the supposition that the policy regime may affect the specification of the model.

\section{References}

Bouquet, O., Boucher, S. \& Logos, G. (2004). Introduction to Stochastic Learning Theory: Advanced Lectures on Machine Learning. Lecture Notes on Artificial Intelligence, 3176, 169-207.

Boyd, S. \& Vandenberg, H. L. (2004). Convex Optimization, Cambridge University Press, Cambridge

Das, A. (2010). Revisiting Sub-optimality of the Decentralized Decision Making: A Note. Journal of Management Research, 2(1), 1-8.

Hastie, T., Tibshirani, R. \& Friedman, J. (2008). Data Mining, Inference and Predict, 2nd edition, Springer Series in Statistics, Germany.

King, R. G. (1993). Will the New Keynesian Macroeconomics Resurrect the IS-LM Model? The Journal of Economic Perspectives, 7(3), 67-82.

Kimball, M. (1995). The quantitative Analysis of the Basic Neomonetarist Model. Journal of Money, Credit and Banking, 27(3), 1241-1277.

Poole, W. (1970). Optimal Choice of Monetary Policy Instruments in a Simple Stochastic Macro Model. Quarterly Journal of Economics, 84(2), 241-301.

Turnovsky, S. J. (1975). Macroeconomic Analysis and Stabilization Policies, Cambridge, Cambridge University Press.

Tinseley, P. A. (1993). Fitting Both Data and Theories: Polynomial Adjustment Costs and Errors - Correction Decision Rules Board of Governors of the Federal Reserve System Finance and Economic Discussion Paper Series, 93-21,

Tsypkin, Y. Z. (1973). Foundations of the Theory of Learning, New York, Academic Press.

Zellner, A. (1971). An Introduction to Bayesian Inference in Econometrics, New York, John Wiley 